Research Article in Science and Society

\title{
The Effects of Quarantine on Depression
}

Aaron Y. Zeng1,*

${ }^{1}$ Atholton High School, Columbia, MD 41044, USA

*Correspondence: aaronz2003@gmail.com

(Received: 09/21/2020; Accepted: 09/21/2020; Published: 10/09/2020)

DOI: https://doi.org/10.37906/isteamc.2020.6

Abstract: The 2020 Covid-19 Virus introduced a new norm into everybody's lives. Among many changes, a significant one was that people were forced to stay inside their homes for days on end, putting many people at high risk for developing mental disorders, such as anxiety, depression, and stress. This paper will specifically focus on depression and combine various sources to analyze how quarantine can lead to depression. This research shows that insufficient sunlight, stressful environments, and lack of human contact are major factors. Furthermore, older adults suffer more due to their low social media usage. This study concludes on how we can prevent this in future pandemics, proposing an app for older adults to use that is simplistic in its design to encourage users of all ages while filtering out stressful news that might cause panic.

Keywords: Isolation, Depression, Situational Depression, Major Depressive Disorder, Quarantine

\section{Introduction}

On March 13th, 2020, citizens around the United States were ordered to stay at home in response to the novel SARS-CoV-2 (Covid-19) Virus. As a result, schools and workplaces shut down, moving all communication to be conducted online. Students needed to adjust to a new online learning environment (Mineo, 2020). Many working-class citizens lost their jobs and had no source of income for months (Morath, 2020). The stock market dipped, crippling the economy. The government worried that the U.S. would fall back into a recession (Schneider, 2020). Despite all these issues, there was a bigger, more silent, problem at hand. Being trapped in the house for days, having little human contact, and hearing the stressful news of the propagating pandemic is a perfect storm for developing depression.

\section{An Overview of Depression}

Depression is a mental disorder that causes one to feel sad and hopeless persistently. It significantly affects one's life, making them uninterested in their favorite activities, school, or work (Mayo Clinic, 2018). It can also negatively affect one's body, such as diminishing a person's appetite, disturbing their circadian rhythm, or even weakening their immune system, making them more susceptible to illness like heart and autoimmune diseases (Gregory, Mak \& McIntyre, 2018). The disorder's duration can range from a couple of weeks to a lifetime, depending on the severity (Harvard Health Publishing, 2018).

There are many forms of depression, but in this paper, only two will be analyzed. The first is called Situational Depression. This form is likely to be triggered after a traumatic event, such as moving or the death of a loved one. The depression is triggered by stress from that event, and usually only lasts for a short period. However, Situational Depression can still have a significant impact on one's life. Patients with this 
disorder may react to normal events that happen in life with more intensity and emotion. They may also feel overwhelmed by or have trouble focusing on things that they do regularly (Cirino, 2018).

The second type of depression is more severe and is called Major Depressive Disorder (MDD). Unlike Situational Depression, MDD is a long-term chronic disorder. Patients feel sadness and emptiness for many days, and they are likely to have symptoms such as an unwillingness to get up in the morning, outbursts of anger over trivial things, and even suicidal thoughts. Consequently, people around those with MDD are more likely to notice their abnormal behaviors. This disorder takes many years of therapy and medical guidance, yet sometimes the treatment helps only a little (Mayo Clinic, 2018).

There are no specific set of causes for depression. Any event or thing can trigger the disorder, and is often different for everybody. However, certain circumstances make it easier for one to develop the disorder. In relation to quarantining due to Covid-19, the social isolation from being inside too long is one of those circumstances. The problems caused by social isolation which can lead to the development of the two depressions mentioned above will be discussed in greater detail in the next section.

\section{The Connection between Isolation and Depression}

The nature of mass social isolation has multiple issues, all of which feed into a dangerous breeding ground for depression. Firstly, being trapped in one's house for days can induce frustration and sadness. This is because a person is less likely to have enough contact with the sun if they are forced to be inside. An insufficient dose of daily sunlight can cause a variety of issues such as skin problems, weak bones, and a lack of Vitamin D. However, most importantly, the body releases less serotonin (Morris, 2019). Serotonin is the neurotransmitter in your brain that is associated with feeling good. With less serotonin, one may begin to feel less happy and be at risk for depression (Scaccia, 2020), likely developing a less intense, short term disorder, like Situational Depression. A solution to this problem could be to take a walk every day, which can be exercise as well as increase one's exposure to the sun.

Secondly, stressful environments are another possible trigger for depression (Cirino, 2018). Stressors can come in a variety of different ways, such as the media or being out in public. For example, the constant droning of news outlets about the dangers of the virus can cause some people to become overly paranoid, causing panic. In other cases, necessary trips outside the house such as going to the grocery store or pharmacy can lead to extreme anxiety. In both these scenarios, one may become obsessive over washing their hands and staying sanitary. They may feel hopeless in trying to control the things that they cannot, which can lead to the development of Situational Depression and may even turn into MDD if not treated correctly. A solution to this problem could be to use food and grocery delivery services which can decrease a paranoid individual's need to be in contact with others.

Lastly, and most importantly, is the lack of human contact. Innately, humans are social creatures, and must maintain constant interaction. "Humans need others to survive. Regardless of one's sex, country or culture of origin, or age or economic background, social connection is crucial to human development, health, and survival" says a professor of psychology and neuroscience at Brigham Young University, Julianne Holt-Lunstad (2017). Without it, people feel unvalued and lonely, and may become distressed after a long period (Novotney, 2019).

An example of this can be seen in sailors, who sail the sea for months with little social interaction. Commercial shipping ranks as one of the deadliest jobs in the world, and among many reasons, isolation contributes to why the job is so dangerous. "...there's the isolation a sailor develops over months at sea, with little to no connection to his loved ones. Losing that safety net can push people to deep, unforgiving depression" says Monique Watanabe, a decorated sailor and lecturer. Isolation at sea can lead to a variety 
of problems. A 2010 review of seafarer deaths found that 25 percent of sailors showed signs of depression while Robert Iversen revealed that an astonishing 6 percent of all deaths were suicides (Kim, 2018).

Though being in quarantine is not as extreme as sailing the seas for months, one can see how social isolation can be dangerous. Additionally, we can use the knowledge learned from commercial shipping to better understand how to prevent depression in mass social isolation. In both scenarios, however, one can see that connection to loved ones is a crucial aspect to thriving.

\section{The Age Factor on Depression}

However, the effects of isolation in relation to depression are generally different based on age. Young people are more likely to be constantly active on social media, so they may feel the loneliness less. In order to explore the effects of quarantine on social media usage in teenagers, a personal study was conducted on Instagram in July, 2020. 116 teenagers responded to the question "How has quarantine affected your use of social media" with three answer choices: "I use social media more," "I use social media less," and "Stayed the same." As illustrated in Table 1, an overwhelming majority of people indicated that their social media usage has increased or stayed the same since the start of quarantine, meaning that teenagers are connecting online at rates higher than ever before.

Table 1. Responses to "How has quarantine affected your use of social media" by 116 teenagers

\begin{tabular}{ccc}
\hline \hline Response & $\begin{array}{c}\text { Number of } \\
\text { People }\end{array}$ & Percentage \\
\hline $\begin{array}{c}\text { I use social } \\
\text { media the } \\
\text { same }\end{array}$ & 17 & $14.7 \%$ \\
$\begin{array}{c}\text { I use social } \\
\text { media more }\end{array}$ & 74 & $63.8 \%$ \\
$\begin{array}{c}\text { I use social } \\
\text { media less }\end{array}$ & 25 & $21.5 \%{ }^{1}$ \\
\hline \hline
\end{tabular}

Unfortunately, this is not the case with mid-aged and older adults. As seen in Figure 1, only 69 percent of adults aged 50-64 use social media, with the percentage falling to 40 past age 65 (Pew Research Center, 2019). However, this is only the percentage of people who have accounts; the numbers for people who routinely use it may be even less. Some reasons for lower rates of social media usage in adults are demanding jobs that leave one with no free time, complicated features on the application that make the user frustrated, or just the fact that no one else around uses social media. Additionally, marketing towards new apps and technology are targeted towards the younger generations, as they are more likely to accept and use it. "...lack of computer skills and heavy web design make elderly struggle as well. Older people also fear of inappropriate content when using social media. Another important finding tells that older users still find it difficult to grasp and understand the purpose of social networking sites" writes Ilona Griniute (2020). Ultimately, online escape is not a viable option for anybody who is no longer young in confinement. Therefore, the older demographic, especially those who live alone or have no friends, are more prone to be isolated and are at higher risk for Situational or Major Depressive Disorder. 


\section{Age group}

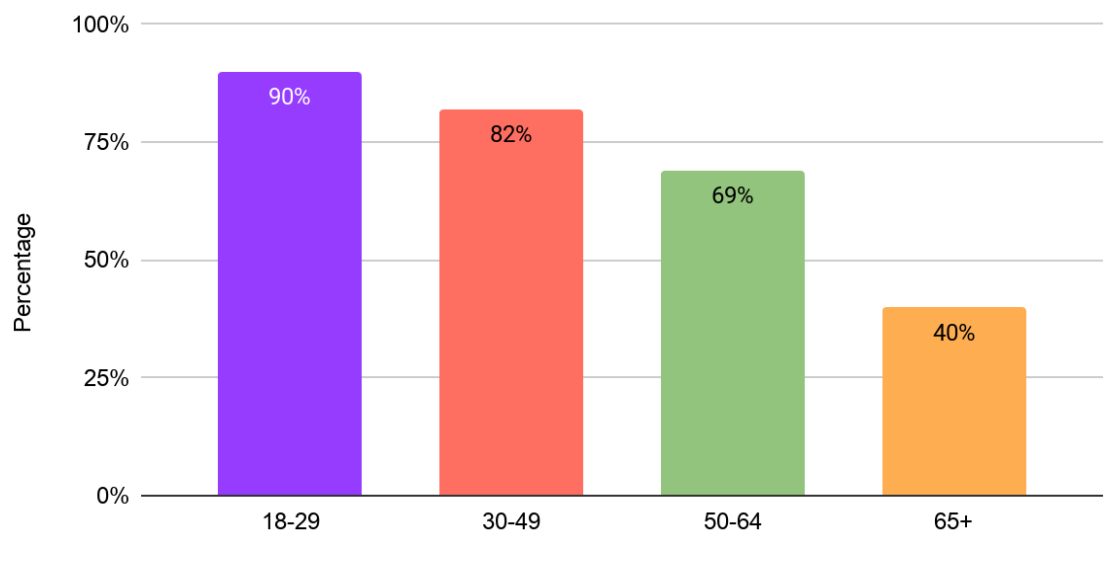

Figure

$$
\text { Age Group }
$$

1. Percentage adults who

use at least one social media site vs. Age Group (Pew Research Center, 2019)

\section{Discussion}

As established above, mid-aged to older adults are most at risk for depression when being isolated, which can be attributed to their inability to replace in-person meetings with online talking, leaving them with no interaction when face-to-face contact is not an option. To prevent this issue from happening in the future, people in this age group should be encouraged to join social media. Though this will not directly cause happiness, social media is an outlet for more connection between individuals, which will help people feel like they are being heard, making them less likely to feel lonely. This sounds like a straightforward plan, but in reality, it is not as easy as it seems. The problem is that many people who are not teenagers have issues with technology. Applications such as Instagram and Snapchat have added many features that allow users to be as creative as possible. However, these very features often confuse older users, which causes them to become frustrated and stop using the app entirely (Griniute, 2020). The solution is to develop an app targeted towards the older generations. The app should be very simple with big fonts, only allowing the user to text or video call their friends. In this way, adults can connect with others while being confined and reduce the effects of isolation in the brain. The app should also filter out stressful news to minimize panic among people who are unable or unwilling to research the topic themselves. This app will help older people connect during isolation, and prevent the development of depression for many individuals.

\section{Conclusions}

Though the idea of social isolation seems scary for many, there are things one can do to help ease the mental toll. For example, taking a walk outside every day is not only good for the body, but can also increase one's vitamin D intake from the sun to ensure high serotonin levels. Additionally, paranoid people should use services that deliver goods to them instead of driving to public places to prevent stress attacks. This simultaneously provides younger people who are less afraid of the virus with jobs. Lastly and most importantly, the increase of social media usage, especially of older adults, will allow for more social 
interaction and give the ability to express feelings to one another, significantly decreasing risk of depression for many.

\section{References:}

Cirino, E. (2018, October 2). Understanding Situational Depression. Healthline.

https://www.healthline.com/health/depression/situational-depression

Gregory, J. M., Mak, M., \& McIntyre, R. S. (2018). Inflammation and Depression in Patients With Autoimmune Disease, Diabetes, and Obesity. ScienceDirect. https://www.sciencedirect.com/science/article/pii/B9780128110737000210\#:\%7E:text=Depression\% 20concurrently\%20increases $\% 20$ the $\% 20$ risk,often\%20undertreated $\% 20 \mathrm{in} \% 20$ these $\% 20$ diseases.

Griniute, I. (2020, April 16). 16 Apr Social media and older people: Promising future? ALL DIGITAL. https://all-digital.org/social-media-older-people-promisingfuture/\#:\%7E:text=Technical\%20difficulties $\% 20$ such $\% 20$ as $\% 20$ a,purpose $\% 20$ of $\% 20$ social $\% 20$ netw orking\%20sites.

Harvard Health Publishing. (2009, December). Managing chronic depression. Harvard Health. https://www.health.harvard.edu/newsletter_article/managing-chronic-depression

Holt-Lunstad, J., Robles, T. F., \& Sbarra, D. A. (2017). Advancing social connection as a public health priority in the United States. American Psychologist, 72(6), 517-530. https://doi.org/10.1037/amp0000103

Kim, E. (2018, December 19). Going Crazy on the High Seas. MEL Magazine. https://melmagazine.com/en-us/story/going-crazy-on-the-high-seas

Mayo Clinic. (2018, February 3). Depression (major depressive disorder) - Symptoms and causes. https://www.mayoclinic.org/diseases-conditions/depression/symptoms-causes/syc-20356007

Mineo, L. (2020, April 10). The pandemic's impact on education. Harvard Gazette. https://news.harvard.edu/gazette/story/2020/04/the-pandemics-impact-on-education/

Morath, E. (2020, June 3). How Many U.S. Workers Have Lost Jobs During Coronavirus Pandemic? There Are Several Ways to Count. WSJ. https://www.wsj.com/articles/how-many-u-s-workers-havelost-jobs-during-coronavirus-pandemic-there-are-several-ways-to-count-11591176601

Morris, N. (2019, October 25). The health dangers of not getting enough sunlight. Metro. https://metro.co.uk/2019/10/25/health-dangers-not-getting-enough-sunlight-10980408/

Novotney, A. (2019, April). The risks of social isolation. American Psychological Association. https://www.apa.org/monitor/2019/05/ce-corner-isolation

Pew Research Center. (2019, June 12). Social Media Fact Sheet. Pew Research Center: Internet, Science \& Tech. https://www.pewresearch.org/internet/fact-sheet/social-media/

Scaccia, A. (2020, June 25). Serotonin: What You Need to Know. Healthline. https://www.healthline.com/health/mental-health/serotonin

Schneider, A. (2020, March 9). NPR Choice page. NPR. https://choice.npr.org/index.html?origin=https://www.npr.org/2020/03/09/813619387/dow-dives1-900-points-nyse-halts-trading-as-stock-indexes-plummet 